\title{
POSTURAL HYPOTENSION
}

\author{
BY \\ TERENCE EAST AND WALLACE BRIGDEN
}

From the Cardiological Department, King's College Hospital

Received March 21, 1946

Postural, or better, orthostatic, hypotension was first described in 1925 by Bradbury and Eggleston. The outstanding symptom, a profound fall in blood pressure on standing up, is one of a triad. The other two, less dramatic, but none the less important and almost constantly present, are anhydrosis and impotence.

The disease is almost entirely confined to males, and only two out of twenty-four reported cases have been women. The age at which symptoms are first noted has been anything from 28 to 70 years.

Accounts of the first appearance of symptoms are not always full, but it is clear that in a fair proportion the first indication of the onset of the disease is anhydrosis; this has sometimes been there for a number of years before the symptoms of hypotension have attracted attention. Impotence appears to come later; usually with or after the hypotension.

\section{REPORT OF A CASE}

The following is an account of the investigation of a case which presented characteristic features.

J. M. was an engineer, aged 57 , married, with four children. He had a severe attack of typhoid at 45; at 49 he suffered from metal poisoning: his occupation at that time led him to handle brass, gun metal, and phosphor-bronze, and sometimes he put a valve of this material in his mouth. Up to the age of 55 he still played tennis. He had felt the cold of recent years.

Syncopal attacks. At the age of 50 he began to suffer from what he called fainting attacks, which came on when he was standing up, never when sitting or lying. Before the attack he used to feel giddy and unsteady; his legs trembled and his hands began to shake, and he could no longer stand up; and he had to drop straight down and sit crouched or leaning forward holding his head down, semi-conscious. Sometimes he lost consciousness. The attack lasted several minutes; after a little he would recover and could go on walking. During the last few years the attacks had become more frequent. Apart from the giddiness, the attacks were not particularly unpleasant; there was no nausea, nor sinking feeling in the abdomen, nor sweating. Usually the attacks were more frequent in the morning than in the afternoon.

Anhydrosis. He had never sweated on his face and for the last four years has not sweated at all. For many years he only sweated on the left side of his body. This had been noted by his fellow workers, for only one side of his shirt became damp.

Impotence. About the age of 37 he became impotent and has had no sexual activity or desire since. He was never constipated.

This account is fairly characteristic of this disorder, and the observations on the blood pressure given below confirm the diagnosis.

Physical examination. A small thin man, rather bent, looking rather younger than his years. Height, 5 feet 2 inches, weight 8 stone 4 pounds. His demeanour was alert and active. His skin was inelastic and dry, with a greyish pallor. The growth and distribution of hair 
was normal. His voice was high-pitched and rather piping. The testes were not atrophied. There was nothing abnormal in the heart or arteries: the skiagram of the chest was normal and so was the cardiogram. All other organs, including the central nervous system, appeared to be healthy. The Wassermann reaction was negative.

\section{The Effect on the Blood Pressure of Changes in Posture}

These observations were made with the patient lying on an electrically operated tippingtable. When tilted from horizontal to $35^{\circ}$ head upwards in 7 seconds, the blood pressure would fall about $40 \mathrm{~mm}$. systolic and $25 \mathrm{~mm}$. diastolic in a minute. The heart rate remained unchanged. The results were much the same when the patient was tilted to $90^{\circ}$ head upwards. After being upright for two minutes the systolic pressure was $50 \mathrm{~mm}$., and the diastolic unreadable.

It was thus possible to study the effect of raising the angle of the body to the horizontal without movement. It was found that the main fall in pressure occurred in the first halfminute. The systolic and diastolic pressures fell about equally, though diastolic readings were hard to obtain; the rate of the heart remained unchanged. There was not much further fall in pressure when the patient was raised to $90^{\circ}$, instead of $45^{\circ}$. These passive alterations in posture caused the blood pressure to fall in much the samefway and to about the same degree each time. The results were typical of numerous observations.

On tilting the patient head downwards, the pressures rose from $110 / 75$ to $145 / 90$ at $35^{\circ}$ head downwards, and to $170 / 90$ at $45^{\circ}$. The rate of the heart did not change. On returning the patient to the horizontal the pressures resumed their original level.

Similar results to these have been noted by many observers. There is no really satisfactory explanation for them. The blood distributes itself in the body under the influence of gravity as though the arterial bed were unprovided with a vaso-constricting mechanism. Further, this lack of adjustment in the arterial bed can be shown by raising one limb.

Effect of raising the arm. With the patient recumbent the pressure was 110/80: when the left arm was raised vertically the brachial pressure fell to $88 / 54$. With an initial higher pressure the fall was the same. Raising the other arm did not affect the blood pressure in the horizontal arm. The fall in pressure, averaging $25 \mathrm{~mm}$., is about equal to the amount of the difference in hydrostatic pressure in the raised arm and the pressure at the level of the heart.

A similar effect was noted when the arm was raised vertically when he was sitting up.

Recumbent, B.P. 85/50. Sitting up, B.P. 70/50

Pressure in arm raised to level of brain, B.P. 45/?

In Sanders' case (1931) similar readings were obtained, although in other respects this patient differed considerably, as is noted elsewhere.

Effect of postural hypotension on the secretion of urine. The tendency to low levels of blood pressure during the day affects the efficiency of the kidneys, and nocturia may be a very troublesome symptom for these patients. For the past six years this man used to pass urine five or six times at night and rarely during the day. The output of urine was recorded over a series of seven consecutive days, the night time being reckoned from 9 p.m. to 9 a.m., the patient being up during the day, and the fluid intake being left to his inclination. The output during the day varied from 10 to $22 \mathrm{oz}$; d during the night from 28 to $50 \mathrm{oz}$. Bradbury and Eggleston (1925) made similar observations.

When resting in bed the blood urea was $67 \mathrm{mg}$. per 100 c.c. The urea clearance was 53 per cent of the average maximum normal. After being up for nine hours, the blood urea was $77 \mathrm{mg}$. per 100 c.c., and the urea clearance fell to 32 per cent of the average standard normal.

In a somewhat atypical case of postural hypotension reported by Corcoran, Browning, and Page (1942) the injection of angiotonin increased the blood flow through the kidneys and the renal excretion. This is the opposite to what is usually found, as the effect is vasoconstriction in normal persons. Presumably the general vaso-constriction improved the renal flow, and outweighed any local constriction of the renal arterioles.

Effect of reducing venous return to the heart. The patient was asked to blow up a column of mercury to $30 \mathrm{~mm}$., and keep it there as long as possible (Flack test). With the patient 
recumbent the B.P. was $112 / 75$ and the pulse 80 . On starting the test the B.P. fell at once to $50 / 35$ and there stayed until the end of the test. After a minute it then rose to $105 / 60$. The pulse rate remained unchanged throughout. Woofter and Deibert (1943) have made similar observations.

The effect of this test is to raise the intrathoracic pressure and reduce the cardiac intake. It would appear that the patient was unable to adjust his arterial system to meet the diminished output. In the normal person this test causes no fall in blood pressure.

When this test was carried out with the patient inclined head downwards, MacLean and Allen (1940) noted that it could be done quite well. The reason for this must be that there is adequate venous return, or that the arterial system is well filled already. The latter is more likely: for when the test is performed by the patient standing, Laufer (1942) found that the fall in blood pressure was more severe than when sitting, or lying, when it was least. It is unlikely that diminished venous return is the sole cause of postural hypotension, as MacLean and Allen (1940) suppose, in view of other evidence.

\section{OTHER OBSERVATIONS}

Sweating. Pilocarpine (1/10 grain) was given hypodermically. Seven minutes later both axillæ were moist, and a minute later both sides of the chest were sweating, likewise the face. As pilocarpine stimulates the sweat glands or the post-ganglionic endings of their sympathetic nerve supply, the response to the drug shows that these structures are intact.

On the other hand, when the patient was put in a hot-air bath for fifteen minutes, he did not sweat. Immersion in water as hot as he could bear caused no sweating on the face. This observation suggests that the anhydrosis is due to a central lesion."

Blood counts. When he first came under observation there was some anæmia-red blood corpuscles, $3 \cdot 2$ million, Hb. 68 per cent, C.I. 1.07. Several blood transfusions were given, and three months later the count was 3.9 million, $\mathrm{Hb}$. 75 per cent. The resting gastric juice contained no acid; after histamine injection there was free $\mathrm{HCl}$. equivalent to 42 c.c. $\mathrm{N} / 10$. A moderate degree of anæmia has rarely been noted in this disease.

Peripheral vasomotor reflexes. In order to get some idea of the site of the lesion in this disease, various peripheral vasomotor reflexes have been investigated. A defective carotidsinus reflex has been thought to be a cause. Vasomotor reflexes depending on stimulation with heat and cold, and the effects of emotional and painful stimuli, have given varying results.

Carotid sinus reflex. Persons vary a good deal in their reaction to pressure on the carotid sinus. In this patient there was very slight slowing and little or no fall in pressure. Other observers have found that the rate may fall along with the pressure in the usual way (Ellis and Haynes, 1936): on the whole the fall in pressure is more notable than the slowing. Stimulation of the sinus with cyanide has produced hyperpnœa (Ellis and Haynes, 1936). It has been suggested that failure of the carotid sinus to react might lead to postural hypotension; but these results show that it is not always incapable of reacting to stimuli, and would exclude it as a cause.

Reaction to cold and other peripheral stimuli. On immersing one forearm in cold water for four minutes the systolic pressure rose in that arm from 57 to 70 , the diastolic remaining below 60 . There was no change in the blood pressure in the other arm. This would appear to be a local reflex action.

Ellis and Haynes (1936) found that cold caused the blood pressure to rise in one patient, and that heat caused normal reflex vasodilatation. Ganshorn and Horton (1934) found that the application of cold caused a rise in blood pressure both when sitting and standing. There was failure to respond to cold in the cases reported by Woofter and Deibert (1943) and Young (1941). Stead and Ebert (1941) found that cooling the skin and painful stimuli such as pinching the skin caused vasoconstriction. Jeffers, Montgomery, and Burton (1941) found that these stimuli had no such effect, and recorded a curious result, that heating the legs and right hand caused thermal vasodilatation in the left hand.

The variable response to these stimuli is difficult to explain. Perhaps the lesion, if central, may not involve the centres concerned; or in some persons there may be reflex 
paths which do not involve the centre. These reflexes may operate through centres in the spinal cord.

Tachycardia. Although nearly all cases of postural hypotension have a pulse rate that varies but little, and does not accelerate under atropine, there are a few in whom tachycardia occurs on standing up. In Sanders' (1932) case the abrupt increase in rate was due to change in the auricular pacemaker.

MacLean and Allen (1940) noted a pronounced rise in rate in a woman who had developed postural hypotension after an extensive sympathectomy; and in a fairly typical case of postural hypotension in a woman with subacute combined degeneration of the cord. There is no mention of the effect of atropine here. Some increase in rate has been noticed on standing up by Stead and Ebert (1941), and by Jeffers, Montgomery, and Burton (1941). Further information is needed about these exceptions to the general rule, particularly as to the effect of atropine. Possibly some variation in the site of the lesion may be the cause. The effect of atropine is recorded below and agrees with that obtained by most observers; also the effect of adrenalin, ephedrine, paredrine, benzedrine, and pituitrin.

Atropine. With a hypodermic injection of $1 / 100$ of a grain, the patient being recumbent, the mouth was dry after five minutes, but the heart rate remained steady at 84 . The blood pressure rose from $85 / 55$ to $115 / 80$. The slight rise in blood pressure is hard to explain. Paralysis of the vagus did not cause any acceleration of the heart due to the unopposed action of the sympathetic. This is in accord with the failure of the heart to accelerate on changes in posture.

Acceleration occurs, however, from the direct effect of sympathetico-mimetic drugs on the heart.

Adrenalin. The effect of $1 / 1000$ adrenalin solution, m. 5 injected hypodermically, the patient being recumbent, was to cause a rise in blood pressure from $130 / 90$ to $155 / 100$ in two minutes, and the heart to accelerate from 88 to 108 ; while $\mathrm{m} .10$ caused the blood pressure, recumbent, to rise to $180 / 120$, and provoked an attack of supraventricular tachycardia lasting twenty minutes, with much tremor and pallor. The patient is evidently very sensitive to these sympathetico-mimetic drugs.

A very severe reaction to 5 minims of adrenalin solution was recorded by Korns and Randall (1937), severe cardiac pain being provoked, which had to be relieved by amyl nitrite. The effect is too short and sharp for therapeutic use.

Ephedrine. In view of the possible therapeutic effect by reason of more prolonged action, the effect of half a grain of ephedrine by mouth was noted. The patient was sitting with the arm dependent. After thirty seconds the blood pressure rose from $78 / 50$ to $120 / 70$, the heart rate rising from 84 to 98 . At the end of four hours the blood pressure was 120/90 and the heart rate 96.

As far as the sitting posture went, there was considerable improvement, and the patient felt well. The effect while standing was less beneficial. Although after the administration of half a grain by mouth the pressure when lying rose to $170 / 105$ from $148 / 98$ in 35 seconds, the rise on standing was to $96 / 68$ from $62 / 45$ in the same time. After two hours the pressure, recumbent, was 155/105; while the standing pressure was $60 /$, the diastolic being unreadable.

Ephedrine stimulates the smooth muscles of the arterioles directly; the effect in this patient, when recumbent, is unusually strong and prolonged considering the dose. It is clear that the vasoconstriction is not adequate to prevent a fall of pressure on standing. But the usual tendency for pressure to rise when recumbent is augmented to a considerable degree. But caution is required with ephedrine, for unpleasant effects have been recorded (Sanders, 1932).

Paredrine. The effect of paredrine was observed. The oral administration of $20 \mathrm{mg}$. caused the blood pressure to rise from $45 / 10$ to $70 / 50$ in about an hour and a half while standing. Lying, the pressure rose from $80 / 50$ to $135 / 110$ in the same time. It would appear to be less effective than ephedrine.

Benzedrine. The observations show a considerable pressor effect, especially when recumbent. There was also a subjective feeling of improvement. A total of $60 \mathrm{mg}$. was given in the course of eight hours. The sitting blood pressure rose from 70/40 to 170/120. The 
standing pressure rose from $35 / 20$ to $100 / 70$. There was a considerable feeling of elation. The pulse rate rose from 88 to 102 . Five hours later the effect had worn off.

The effect of this drug is unusually intense and prolonged, and similar in this respect to the others of this group. A smaller dose of $22.5 \mathrm{mg}$. given in two hours caused the standing pressure to rise from $60 / 50$ to $105 / 85$; the sitting pressure from $70 / 54$ to $145 / 115$, and the lying pressure from $120 / 95$ to $180 / 130$. The first two doses of $7 \cdot 5 \mathrm{mg}$. produced but little effect.

Pituitrin. Stimulating the unstriped muscle of the arterioles caused slight rise in blood pressure, and slight acceleration, as one might expect: 0.3 c.c. caused the blood pressure to rise, when recumbent, from $90 / 55$ to $125 / 90$ in two minutes: the pulse rate rose from 70 to 90 .

Sweating. The anhydrosis is sometimes unilateral, as it was in this case, the right side being affected thirteen years before the other. The statement that he had never sweated on his face may be inaccurate, or may indicate that the lesion began quite early in life. Ghrist and Brown (1928) noted unilateral anhydrosis several years before the other symptoms. In Laplace's case (1942) the sweating was intermittent, apparently varying with the blood pressure: when the pressure could be made to rise, as in exercising the muscles of a limb to which a tourniquet had been applied, sweating returned. Korns and Randall (1938) found that when large doses of benzedrine were given sweating returned. There was, however, no response to pilocarpine (1/8 of a grain) given by mouth.

There was a return of sweating in a patient of MacLean and Allen (1940) who was treated by raising the head of the bed; this appeared to be accompanied by improvement in the reaction of the blood pressure to standing. A tendency to increased sweating on one side of the body while sitting still was noted by Riecker and Upjohn (1931).

In nearly all cases the sweat glands, or the autonomic nerve endings in them, respond to pilocarpine. The erratic distribution of the areas of anhydrosis needs further study in orthostatic hypotension. It may be that in the hypothalamus, lesions occur that correspond to certain body areas. The unilateral anhydrosis suggests this, and more detailed delineation of these areas might be profitable. The suggestion that the level of the blood pressure may affect sweating is interesting, but there may be actually improvement in parallel functions.

Impotence. Loss of libido and sexual activity is recorded in almost all the male cases; this has occasionally appeared as quite an early symptom. Benzedrine produced an improvement according to Korns and Randall (1938). As some of the patients have had such diseases as tabes dorsalis the defect may have been due to this cause, apart from the lesion peculiar to hypotension; but as it occurs in others with no apparent lesion of the central nervous system, it may be due to a hypothalamic lesion. Much more information is needed about the pathogenesis of this symptom.

\section{NATURe of Postural Hypotension}

There is no control of the distribution of the blood in the arterial system. The blood behaves as though the arteries had no vaso-constrictor control. When the patient stands up blood tends to pool below the level of the heart. But Stead and Ebert (1941) have shown that the proportion of the total blood volume contained in the legs in cases of postural hypotension agrees closely with that present in normal persons. The conclusion is that an excessive degree of pooling does not occur. If the normal tendency to pooling be prevented by putting tourniquets on the legs, the brachial pressure does not fall in these patients. In the same way the application of external hydrostatic pressure by standing the patient in water up to the heart will prevent the pressure falling. Stead and Ebert (1941) conclude that the cause of this disorder is an " abnormal response to the pooling of a normal quantity of blood." The nature of this abnormal response has been investigated by these observers by noting that the flow of blood in the hand did not decrease as the pressure fell. This would point to a failure in the compensatory vaso-constriction, which in the normal person prevents a fall in blood pressure on standing up. Jeffers, Montgomery, and Burton (1941) confirmed that the flow of blood in the fingers of a patient with postural hypotension did not decrease on standing up, as it does in normal persons.

The rise in blood pressure which occurs in the arm when the patient is tilted head downwards shows that there is lack of control over the distribution of the blood. The fall in 
blood pressure in one arm when the limb is raised, the patient being recumbent, illustrates, in one limb, what occurs in the body as a whole.

Site of the lesion. The peripheral vessels can be made to constrict by the action of vasoconstrictor drugs, so the defect does not lie in their musculature nor in their sympathetic nerve endings. In most cases vaso-constrictor reflexes acting through the sympathetic ganglia, such as may be elicited by painful stimuli, are intact. Changes of temperature in other parts of the body still cause vaso-dilatation or constriction elsewhere.

The failure in postural vaso-constriction is associated with a fixed heart rate in the large majority of cases, as shown by the inability to accelerate under atropine, or when the blood pressure falls. With this are associated anhydrosis and impotence. To account for this triad it seems necessary to look for some central site. Ellis and Haynes (1936), Wooften and Deibert (1943), and Young (1941) have stressed the association of this disease with diseases of the central nervous system, such as tabes dorsalis and encephalitis. The general consensus of opinion seems to be that the hypothalamus is the most likely site. So far there is no postmortem evidence on the subject. The lesion must vary in extent and site, so that one can account for the exceptional cases in whom there is tachycardia on standing.

Apart from the central site, there are patients in whom there have been lesions of the cord such as hæmatomyelia, syringomyelia, and transection. Here it may be argued that either the afferent paths or the efferent paths might be interrupted. Very extensive sympathectomy may produce a similar result.

Treatment and Prognosis. This is not very satisfactory and at the most is only palliative. Following the observation that the patient was usually better in the latter part of the day, perhaps because some sort of adjustment had been achieved, MacLean and Allen (1940) have advocated sleeping with the head of the bed raised, so that the patient was never really horizontal. In the patient here described this made no difference; but he was unusual in being but little better towards evening in any case.

Bandages and binders are not practical if used so that they really check the tendency to pooling.

Patients seem to have to reduce exertion to a minimum in warm weather, and to avoid standing still. Shifting the feet and shuffling movements (Croll and Duthie, 1935) seem to lessen the tendency to fall in pressure.

Drugs. The vaso-constrictors have a certain value. That they cause a considerable rise in pressure in some cases when recumbent has been shown. In fact, adrenalin tends to be too violent in its action.

In spite of the rise in pressure when the patient is lying down, the fall still occurs when he stands up. But nevertheless, the effect on the patient is less, and the fall may be less severe. They are therefore worth while. The choice seems to lie between ephedrine, paredrine, and benzedrine. For the patient described a combination of benzedrine $5.0 \mathrm{mg}$. at 8,9 , and 11 a.m., and ephedrine $30 \mathrm{mg}$. at 1, 3, and 5 p.m., seemed to work best and helped him to get through the day fairly well. It is best to give the benzedrine early, as it seems to induce a feeling of well-being soon in the day and does not cause insomnia. Korns and Randall (1938) gave 80 to $100 \mathrm{mg}$. of benzedrine in the morning and paredrine $40 \mathrm{mg}$. every two hours till 2.30 p.m., up to $160 \mathrm{mg}$. By this means sweating and sexual activity returned.

Prognosis. The disease appears to run a prolonged course. Having reached a certain degree of severity it does not become worse. There is so far no record of fatal results. It would be interesting to know what has happened to those patients described ten years ago or more. In some instances the associated disease of the nervous system may be of a progressive character. Laplace (1942) described a case with a prolonged remission.

\section{SUMMARY}

A case of orthostatic or postural hypotension is described.

Observations are recorded on the effects of posture on the brachial blood pressure.

The effects of sympathetico-mimetic drugs are recorded.

The stability of the heart rate under atropine and on changes in posture is noted. lesion.

The nature of the defective vasomotor control is discussed and the possible site of the 
Attention is drawn to the associated symptoms of anhydrosis and impotence, which form a triad.

Benzedrine and ephedrine provide palliative relief.

\section{REFERENCES}

Bradbury, S., and Eggleston, C. (1925). Amer. Heart J., 1, 73.

Corcoran, A. C., Browning, J. S., and Page, I. H. (1942). 'J. Amer. med. Assoc., 119, 793.

Croll, W. F., and Duthie, R. J. (1935). Lancet, 1, 194.

Ellis, L. B., and Haynes, F. W. (1936). Arch. intern. Med., 58, 773.

Ganshorn, J. A., and Horton, B. T. (1934). Proc. Mayo Clin., 9, 541.

Ghrist, D., and Brown, G. (1928). Amer. J. med. Sci., 75, 336.

Jeffers, W. A., Montgomery, H., and Burton, A. C. (1941). Ibid., 202, 1.

Korns, H. M., and Randall, W. L. (1938). Ann. intern. Med., 12, 253.

Laplace, L. B. (1942). Ibid., 17, 339.

Laufer, S. T. (1942). J. Canad. med. Assoc., 46, 160.

MacLean, A., and Allen, E. (1940). J. Amer. med. Assoc., 115, 2163.

Riecker, H. H., and Upjohn, E. G. (1931). Amer. Heart J., 6, 225.

Sanders, A. O. (1932). Ibid., 7, 808.

Stead, E. A., and Ebert, R. V. (1941). Arch. intern. Med., 67, 546.

Woofter, A. C., and Deibert, A. V. (1943). Amer. J. Syph. Ven. Dis., 27, 616.

Young, R. H. (1941). Ann. intern. Med. 15910. 